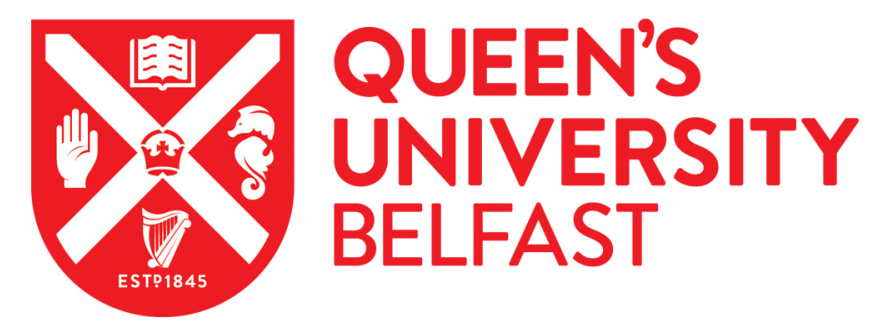

\title{
Psychometric validation of the Prenatal Distress Questionnaire (PDQ) in pregnant women in Spain
}

Caparros-Gonzalez, R. A., Perra, O., Alderdice, F., Lynn, F., Lobel, M., García-García, I., \& Peralta-Ramírez, M. I. (2019). Psychometric validation of the Prenatal Distress Questionnaire (PDQ) in pregnant women in Spain. Women \& Health. https://doi.org/10.1080/03630242.2019.1584143

Published in:

Women \& Health

Document Version:

Peer reviewed version

Queen's University Belfast - Research Portal:

Link to publication record in Queen's University Belfast Research Portal

Publisher rights

( 2019 Taylor \& Francis. This work is made available online in accordance with the publisher's policies. Please refer to any applicable terms of use of the publisher.

\section{General rights}

Copyright for the publications made accessible via the Queen's University Belfast Research Portal is retained by the author(s) and / or other copyright owners and it is a condition of accessing these publications that users recognise and abide by the legal requirements associated with these rights.

Take down policy

The Research Portal is Queen's institutional repository that provides access to Queen's research output. Every effort has been made to ensure that content in the Research Portal does not infringe any person's rights, or applicable UK laws. If you discover content in the Research Portal that you believe breaches copyright or violates any law, please contact openaccess@qub.ac.uk. 
Running head: VALIDATION OF THE PDQ IN PREGNANT WOMEN IN SPAIN

Psychometric Validation of the Prenatal Distress Questionnaire (PDQ) in Pregnant Women in Spain

\begin{abstract}
The Prenatal Distress Questionnaire (PDQ) was developed among English-speaking women in the United States to assess specific worries and concerns during pregnancy. Our aim was to analyze the factor structure of the PDQ, using confirmatory factor analysis, and assess its convergent validity in Spanish women. A sample of 233 pregnant women with ages ranging from 19 to 42 years in the south of Spain (Europe) (J anuary 2015 - March 2016) completed the translated PDQ, the Perceived Stress Scale (PSS) and the Symptom Checklist-90-revised(SCL-90-R). Confirmatory factor analysis revealed a three-factor structure supporting the original PDQ factor structure $\left(x^{2}(31)=55.43, p=0.004 ; \mathrm{CFI}=0.96\right.$; $\mathrm{RMSEA}=0.058 ; \mathrm{WRMR}=$ 0.702). The Spanish PDQ significantly correlated with the PSS and SCL-90-R (r's 0.18 - 0.49, p's <0.05), providing evidence of convergent validity. These results illustrate that the stress dimensions investigated by the PDQ adequately represent pregnant women's distress across a different cultural context and corroborate the psychometric properties of this instrument previously demonstrated in Englishspeaking women. The Spanish version of the PDQ can be used by clinical practitioners to evaluate specific worries and concerns women experience during pregnancy.
\end{abstract}

Keywords: Pregnancy; Stress; Questionnaire; Structure; Factor analysis 


\section{Introduction}

Pregnancy is a time of adaptations, which can lead to considerable stress (Lynn et al. 2011; Gourounti et al. 2016). Maternal stress during pregnancy has been related to adverse pregnancy outcomes such as anxiety, low birth weight, prematurity, and poor infant neurodevelopment (Duthie and Reynolds 2013; Lobel and DunkelSchetter 2016; Razurel et al. 2017).

The Royal College of Midwives declared that excessive and persistent levels of stress can lead to psychological and physical illnesses, anxiety and depression (RCM 2018). It is estimated that up to $25 \%$ of women suffer from stress during pregnancy (Matvienko-Sikar and Dockray 2017). Further, the prevalence of antepartum anxiety and depression among pregnant women is $17 \%$ and $10.3 \%$ respectively (Gelaye et al. 2017; Nath et al. 2018). According to the National Institute for Health and Care Excellence (NICE), every pregnant women should be assessed their emotional health, including stress levels, during pregnancy (Henderson, J omeen, and Redshaw 2018; NICE 2014).

As pregnancy is a major life event, pregnancy-specific stress may be more strongly associated with adverse outcomes than general stress (Alderdice and Lynn 2009; Lobel et al. 2008; Lobel and Dunkel-Shetter 2016). Pregnancy-specific stress refers to pregnant women's concerns about physical symptoms, the health of the fetus, labor, relationships, and parenting (Alderdice, Lynn, and Lobel 2012). Among 
Running head: VALIDATION OF THE PDQ IN PREGNANT WOMEN IN SPAIN

15 questionnaires identified to measure pregnancy-specific stress (Alderdice, Lynn, and Lobel 2012), the Prenatal Distress Questionnaire (PDQ) (Yali and Lobel 1999) has been used in a wide range of studies and has been recommended to assess stress related to pregnancy (Nast et al. 2013). In addition to the original English version used in the U.S., Ireland and the United Kingdom (Alderdice et al. 2013; Gennaro, Shults, and Garry 2008; Heberlein et al. 2016; Lobel et al. 2000; Lynn et al. 2011; Yali and Lobel 1999), the PDQ has been translated in German samples (Bolten et al. 2011; Koletzko, La Marca-Ghaemmaghami, and Brandstätter 2015; Pluess et al. 2010). Two studies have explored the factor structure of the PDQ in Englishspeaking low and high-risk pregnant women (Alderdice and Lynn, 2011; Alderdice et al. 2013), and it was found to be stable with three factors identified: "Concerns about Birth/Baby," “Concerns about Weight/Body Image," and “Concerns about Emotions/ Relations". Convergent validity with the Perceived Stress Scale (PSS), the State-Trait Anxiety Inventory-State (STAI-S), and the Edinburgh Postnatal Depression Scale (EPDS) has been demonstrated (Alderdice, Lynn, and Lobel 2012). The original PDQ (Yali and Lobel 1999) has not been administered to Spanishspeaking samples.

The aim of the present research was to translate the PDQ into Spanish, analyze its factor structure using Exploratory Factor Analysis (EFA) and Confirmatory Factor Analysis (CFA), and assess its convergent validity when applied to pregnant women in Spain. Because dimensionality of the PDQ has only been explored across two studies (Alderdice and Lynn, 2011; Alderdice et al. 2013) and the three underlying dimensions identified by these studies are considered to display construct validity 
(Alderdice, Lynn, and Lobel 2012), we first used EFA for investigating the structure of the scale. Then, Confirmatory Factor Analysis was performed with the aim of examining how closely the three-factor structure adequately represents the patterns of responses in our Spanish sample. In this way, our overarching aim was to investigate whether these factors embody significant facets of women's experiences of pregnancy in a different cultural context.

\section{Methods}

\section{Sample}

This study was based on data from a longitudinal study of perinatal stress in Spain (GESTASTRESS) (Caparros-Gonzalez et al. 2018). Eligible participants were low-risk pregnant women, proficient in the Spanish language, and over 18 years old. Participants were identified and recruited by two community midwives (J anuary 2015 - March 2016) while attending a prenatal appointment at two Health Centersin the south of Spain. The two midwives screened potential participants for eligibility according to medical data in the Pregnancy Health Document (Andalusian Ministry of Health 2010), which is the official record of every pregnant woman in Spain. A total of 305 pregnant women were approached to participate, and 288 women consented to participate. Subsequently, six women were excluded (pregnancy ended in miscarriage); 37 declined to participate, after initially agreeing to collaborate, referring to lack of time, and 12 were excluded because they provided only sociodemographic information. This resulted in a final sample of 233 women, which was above the minimum sample size required to conduct both an EFA and a CFA: At 
Running head: VALIDATION OF THE PDQ IN PREGNANT WOMEN IN SPAIN

least 10 participants per estimated item is the general consensus (Schreiber et al. 2006). All 233 participants completed each of the PDQ items with no missing data.

\section{PDQ translation procedure}

This process was performed in accordance with international guidelines for crosscultural adaptations of questionnaires (Epstein, Santo, and Guillemin 2015; Martin and Savage-McGlynn 2013).

An expert team in perinatal health and proficient in both languages translated the PDQ into Spanish separately (Version 1). Version 1 was translated back into English (Version 2) by a professional translator-editor. According to the expert team, Version 2 was grammatically and semantically equivalent to the original questionnaire. No variability was found among versions. A pilot sample of 40 participants completed the final translated version and found it easy to understand and adequately reflected their concerns. No further changes were made following piloting.

\section{Study instruments}

The Prenatal Distress Questionnaire (PDQ) is a 12-item scale to assess specific worries and concerns during pregnancy regarding physical symptoms, relationships, parenting, medical problems, labor and delivery, and the health of the baby (Yali and Lobel 1999). The psychometric properties reported for the PDQ substantiate its reliability and validity (Alderdice et al. 2013; Gennaro, Shults, and Garry 2008; Lobel et al. 2000; Lynn et al. 2011; Pluess et al. 2010; Yali and Lobel 1999). Responses are on a 5-point Likert scale from 0 (Not at all) to 4 (Extremely). Responses to the12-item PDQ are summed, providing a prenatal distress score ranging from 0 to 48. 
The convergent validity of the PDQ was assessed through two psychosocial stress instruments:

The Perceived Stress Scale (PSS): The Spanish version of the 14-item Perceived Stress Scale (PSS) (Cohen, Kamarck, and Mermelstein, 1983; Remor 2006) was used to assess perceptions of general stress during the last month. Responses are on a 5-point Likert scale from 0 (never) to 4 (very often). The Cronbach's alpha reliability coefficient of the Spanish version is $a=0.81$.

The Symptom Checklist-90-Revised (SCL-90-R) (Caparros-Caparros et al. 2007; Derogatis 1994): This scale is used to assess psychopathological symptoms and has been translated into 26 languages. It consists of 90 items scored by a 5-pointLikert scale from 0 (never) to 4 (extremely) and is used to assess nine dimensions:

Somatization, Obsession Compulsion, Interpersonal Sensitivity, Depression, Anxiety, Hostility, Phobic Anxiety, Paranoid Ideation, and Psychoticism. The scale also has three global indexes of distress: GSI (overall psychological distress), PSDI (intensity of symptoms) and Positive Symptom Total (number of self-reported symptoms). The Cronbach's alpha reliability coefficients of the Spanish version range from 0.67 to 0.94 .

Socio-demographic and obstetric data were collected from the Pregnancy Health Document (Andalusian Ministry of Health 2010).

\section{Data Analysis}

Data were analyzed using Stata 13 (StataCorp 2013). The appropriateness of the factor model was checked using the Kaiser-Meyer-Olkin (KMO) and Bartlett's test of sphericity. KMO test was applied to assess the sample size adequacy (KMO values 
Running head: VALIDATION OF THE PDQ IN PREGNANT WOMEN IN SPAIN

between 0.7 and 0.8 are good). Bartlett's test of sphericity was used to assess whether the correlation between variables was different from zero. Bartlett's test of sphericity must be significant ( $p<0.05$ ) (Field, 2009). Bartlett's test of sphericity $\left(x^{2}(1)=541, p\right.$ $<0.001)$ and the Kaiser-Meyer-Olkin $(K M O=0.76)$ to test the three-factor structure described previously (Alderdice and Lynn 2011; Alderdice et al. 2013) were satisfactory. Components with eigenvalues over Kaiser's criterion of 1 were selected as factors (Braeken \& Van Assen, 2017). The principle underlying EFA and CFA is that items are indicators of latent constructs, i.e., constructs that cannot beobserved directly. For example, we cannot observe intelligence directly, but we can infer the level of someone's intelligence by observing her performance across a number of tasks (items). The assumption is that the performance in these tasks will be correlated. Performance in a task (or answer to an item) is therefore the result of the underlying ability (e.g., intelligence) (Field, 2009).

First, an EFA, using maximum likelihood and the oblimin rotation method with Kaiser normalization, was conducted on half of the sample $(n=116)$ for searching the structure of the scale (Field, 2009). Half of the sample was randomly selected at a 1:1 ratio by means of an Excel RAND function (Microsoft Excel, 2010). Many items in the questionnaire displayed skewed and asymmetric distributions. To allow for this skewness and asymmetry, we conducted Confirmatory Factor Analysis using a Weighted Least Squares Means and Variance adjusted (WLSMV) estimator, which is more adequate in analyzing categorical data with non-normal distributions than MaximumLikelihood (ML) estimators (Beauducel and Herzberg 2006; Rhemtulla, BrosseauLiard, and Savalei, 2012). Analyses were run using Mplus 7.1(Muthén and Muthén 
2013): Model fit was assessed by using the Likelihood ratio $x^{2}$ of the model of interest compared against the saturated model: A non-significant result is indicative of good model fit with the data (Acock 2013). We also used other goodness of fit indicators including the Comparative Fit Index (CFI), with values over 0.95 indicating good fit of the model; the Root Mean Squared Error of Approximation (RMSEA), with values less than 0.05 indicating a close fit; and The Weighted Root Mean Squared Residuals (WRMR), with values less than 1 indicating good fit (Hu and Bentler 1999).

We estimated factor scores in the latent dimensions of the CFA model with the best fit. Relationships between these factor scores and other concurrent measures of anxiety and mental health variables were assessed using Pearson correlations to test convergent validity, which provides information about the extent to which two instruments measure a similar construct (Carlson and Herdman 2012).

\section{Ethics}

The Human Ethics Research Committee of the University of Granada (reference 881), the Biomedical Ethics Research Committee and the Ethics Research Committee of the Health Centers, and the hospital where this study was implemented approved the study protocol. This study was conducted according to the guidelines of the Helsinki Declaration (AMM, 2008) and the Good Clinical Practice Directive (Directive 2005/28/EC) of the European Union. Participation was voluntary, and every participant read and signed an informed written consent document.

\section{Results}

Sample characteristics and descriptive statistics 
Running head: VALIDATION OF THE PDQ IN PREGNANT WOMEN IN SPAIN

The majority of participants were between 26 and 35 years old, from Spain, married or co-habiting, working part-time, with no previous miscarriages and wanted to be pregnant (Table 1). The Spanish PDQ mean scores and standard deviations (in brackets) in our sample are presented from the lowest distressing (handling the baby after coming home from hospital) to the most distressing (the possibility of having an unhealthy baby) (Figure 1).

(Please place Table 1 about here)

(Please place Figure 1 about here)

\section{Exploratory Factor Analysis}

Statistical analysis using EFA indicated that three components had eigenvalues over Kaiser's criterion of 1 (Braeken \&Van Assen, 2017), explaining in combination $34.37 \%$ of the variance. Item selection was performed by excluding items with loadings < 0.32 (Nues et al., 2016). [Table S1 shows the factor loading afterrotation.] The items that clustered on the same components were: Factor 1 represents Birth Concerns (items 3, 9, 10, 11, and 12), Factor 2 Relationships (items 4, 5, and 8) and Factor 3 Physical Symptoms (items 1, 2, and 7). Item no 6 did not load on any factor and was thus excluded from the identified factors. Goodness of fit indicated significant model fit, $x^{2}(33)=59.12, p=0.346$. Item 6 did not load in any factor, so we decided to exclude it from our factors.

\section{Confirmatory Factor Analysis}

Confirmatory Factor Analysis on half of the sample $(n=117)$ revealed Factor 1 refers to Birth Concerns (items 3, 9, 10, 11, and 12), Factor 2 Relationships (items 4, 5, and 8) and Factor 3 Physical Symptoms (items 1, 2, and 7). This structure is identical to the 
one identified in the EFA conducted in this study. This three-factor structure is the same as described in previous studies (Alderdice and Lynn 2011; Alderdice et al. 2013), except for item 2 , which was excluded in a previous study (Alderdice and Lynn 2011), due to not loading on any factor. The three-factor structure indicated a good fit of the model $\chi^{2}(32)=40.42, p>0.01 ; C F I=0.955 ;$ RMSEA $=0.048 ;$ WRMR $=$ 0.058 .

Then, we tested the three-factor structure model reported by Alderdice and Lynn (2011) using the complete sample $(\mathrm{N}=233)$. Factor 1 was made up of items reflecting concerns over the baby and giving birth (items 3, 6, 9, 10, 11 and 12); factor 2 was constituted from items reflecting worries about body and weight (items 1, 2, and 7); and factor 3, reflecting concerns about relationships and emotions (items 4, 5 and 8). Consistent with the previous study (Alderdice and Lynn, 2011), item 2 (physical symptoms) was excluded from the model as it did not load on any factor (Model 1 , Table 2). Although excluding item 2 improved goodness of fit statistics, improvements were still needed (Model 2, Table 2). Successively, we considered item 6 (concerns about eating a healthy and balanced diet) may be a culturally-sensitive item (in countries with a traditional Mediterranean diet (such as Spain) that is low in saturated fat and in which fresh fruit and vegetables are more easily available (Willett et al. 1995), individuals may have less concerns and emphasis on healthy eating during pregnancy compared to North-European countries. Indeed, excluding item 6 from the scale resulted in an improvement of fit (Model 3, Table 2), although the fit obtained was still not adequate. 
Due to associations between concerns about emotions and concerns about relationships (Rosand et al. 2011), in Model 4 we tested the inclusion of a correlation between the error terms of item 4 (concerns about emotions) and item 5 (concerns about relationships). Due to reported associations between prematurity and the health of newborns (NICE 2015), an association between the error terms of item 9 (concerns about health of newborn) and item 11 (concerns about birth before term) was assessed in Model 4. The results of this final model indicated a good fit of the model (Model 4, Table 2). (Please place Table 2 about here)

All the associations between indicators and underlying factors were statistically significant ( $p<0.001$ ). Bivariate correlations of the three factors were allstatistically significant ( $p<0.01$, Figure 2). Factor 1 (Birth Concerns) correlated with Factor2 (Physical Concerns) $(r=0.35 ; p<0.001)$. Factor 1 (Birth Concerns) correlated with Factor 3 (Relations Concerns) ( $r=0.71 ; p<0.001)$. Factor 2 (Physical Concerns) correlated with Factor 3 (Relations Concerns) $(r=0.68 ; p<0.001)$. (Please place Figure 2 about here)

Although the CFA supported the presence of three underlying factors, the PDQ has been used as a uni-dimensional scale, assuming a single underlying factor. We also tested the fit of a model whereby all 10 items considered above were assumed to be indicators of a single underlying factor. Once we modelled some additional associations between error terms (items 9 and 10; 9 and 11; 10 and 11; 1 and 7; 4 and 5), the fit indices overall indicated adequate model fit, $x^{2}(30)=55.7, p>$ 0.05; $C F I=0.95 ; R M S E A=0.061 ; W R M R=0.710$. To compare the three-factor model 
and the one-factor model, we ran these models using an MLR estimator in Mplus 7.1 (Muthén and Muthén 2013). The information criteria of the uni-dimensional and tridimensional model were very similar $(B I C=6190.4$ and $B I C=6190.3$; $A I C=6069.6$ and $A I C=6069.5$ for the uni-dimensional and tri-dimensional models respectively), suggesting that the one-factor and three-factor models provided comparable fit to the data.

\section{Evidence of convergent validity}

Pearson's correlations to test convergent validity between the PDQ, the PSS and the SCL-90-R indicated that the three PDQ factors and the one-factor solution were significantly (all $p$ values $<0.01$ ) positively correlated with the PSS and the SCL-90-R (Table 3).

(Please place Table 3 about here)

Results did not indicate significant associations of factor scores in the three dimensions with age or marital status (all ANOVAs $p>0.05$ ). Women pregnant for the first time reported higher Birth Concern (Mean = 7.56 compared to Mean =5.72 for multiparous women), $t(150)=3.63, p<0.05$. Indeed, parity was significantly inversely related to Birth Concern factor scores $(B=-0.23, p=0.007)$, even when we controlled for age and marital status, $F(4,146)=2.85, p=0.026$, adjusted $R^{2}=0.05$. No significant differences were found between primiparous and multiparous women for the other factors.

Considering the 12 items of the questionnaire, the Cronbach's alpha was $a=0.743$.

The change in Cronbach's alphaby deleting an item from the scale and inter-total 
correlation matrix were satisfactory with internal consistency values in the range 0.696-0.756

(Table 4).

(Please place Table 4 about here)

\section{Discussion}

The PDQ is a valuable psychometric instrument used to assess pregnancy-specific stress related to pregnancy (Alderdice, Lynn, and Lobel 2012; Auerbach et al. 2017; Kerry et al. 2015; Nast et al. 2013). Although it has not been adapted to Spanishspeaking countries yet, the Revised Prenatal Distress Questionnaire (NuPDQ), a slightly expanded (17-item) version (Lobel et al. 2008), has already been translated and applied to Latin-American (Arroyo 2013; Coussons-Read at al. 2012;

Chaponniere 2009) and Turkish (Yuksel, Akin, and Durna 2014) women. Nevertheless, no publications of which we are aware have reported the use of the original PDQ in Spanish-speaking samples. The aim of this study was to confirm the three-factor structure of the Spanish version of the original PDQ and report evidence of convergent validity among pregnant Spanish women.

Consistent with previous studies (Alderdice and Lynn 2011; Alderdice et al 2013), the CFA revealed a three-factor structure. Factor 1 (Birth Concerns) (items 3, 9, 10, 11 and 12); factor 2 (Relations Concerns) (items 4, 5 and 8); and factor 3 (Physical Concerns) (items 1 and 7). Covariances between errors in items 9 (unhealthy baby) and 11 (premature birth) and between items 4 (emotional concerns) and 5 (relationships) were included in our final model. Based on the content of these items, their overlap appears sensible and suggests that they share some common meaning beyond what they share with other items on the stress factor where they loaded. 
We excluded item 2 (physical symptoms) because it did not load on its underlying factor (Physical Concerns). A similar result was reported by Alderdice and Lynn (2011) with low-risk pregnant women. A CFA conducted on high-risk pregnant women (Alderdice et al. 2013) included item 2 in the Physical Concerns factor, although it exhibited the lowest loading. These differences that correspond to sample characteristics suggest that worries about physical symptoms may not be related to other indicators of pregnancy-specific stress in low-risk pregnancies, particularly during the second trimester. Furthermore, to improve model fit in the present study, item 6 (eating healthy food) was not included, as it was not significantly associated with any of the three factors. In countries with a traditional Mediterranean diet (such as Spain) that is low in saturated fat and where fresh fruit and vegetables are more easily available (Willett et al. 1995), individuals may have less concerns and emphasis on healthy eating during pregnancy compared to North-European countries, which traditionally have adopted diets rich in saturated fat.

A uni-dimensional factor structure was found to have good fit, revealing this instrument can be used to evaluate a single underlying construct, namely pregnancyspecific stress. Pregnancy-specific stress is manifested by high stress levels related to the health of the fetus, medical symptoms, labor and delivery and parenting, and is a major risk factor for preterm birth and fetal growth restriction that can alter fetoplacental hemodynamics (Levine et al. 2017). Prior studies have underscored the importance of assessing pregnancy-specific stress, given its association with healthimpairing behaviors during pregnancy and with adverse perinatal outcomes (Auerbach, Lobel, and Cannella 2014; Coussons-Read et al. 2012; Lobel et al 2008). 
Incorporating brief and robust psychological questionnaires, such as the PDQ, into clinical care may improve the identification of women at risk of high levels of prenatal stress and promote healthier birth outcomes (Cannella, Auerbach, and Lobel, 2013).

The convergent validity between the Spanish version of the PDQ and other constructs appeared to be good. All three factors were significantly correlated with the PSS. This finding corroborates previous research using the English version of the PDQ, which was positively correlated with the PSS (Lobel et al. 2000; Yali and Lobel 1999). Although previous studies have used the SCL-90-R with pregnant women (Peñacoba et al. 2017), the present study is the first of which we are aware to explore and find significant correlations of PDQ factors with the SCL-90-R. However, even the strongest correlations were of moderate magnitude (approximately 0.4), suggesting that while pregnancy-specific stress is significantly related to general stress and to emotions such as anxiety and depression, this type of stress is still sufficiently independent to be defined as a unique construct (Yali and Lobel, 1999). With this in mind, the Spanish version of the PDQ appears to be an adequate measure to assess pregnancy-specific stress, as that level of stress women have during pregnancy specifically related to physical symptoms, health of the fetus, relationships, labor and delivery and emotional well-being (Lobel et al. 2000; Yali and Lobel 1999.)

Although the internal consistency of the three factors was below 0.7 , the Cronbach's alpha is a measure that depends on the observed correlation of the items and the number of items, not taking into account error variance of the items. CFA 
allows isolating the variance items share with an underlying dimension from the error variance of the individual items, thus providing a reliable measure of the underlying dimension (Acock 2013).

The Spanish version of the PDQ is a brief measure with good psychometric properties that provides information about the worries and concerns of pregnant women both in clinical and research settings. Although it was first developed to assess overall levels of pregnancy-related stress, the three-factor structure reported in this study gives evidence of the additional detail that can be collected when using this measure. Although the results of this study suggest that ten items were sufficient as indicators of the three underlying constructs, the two items excluded (physical symptoms and eating healthy foods) may be important independent contributors to prenatal stress, and we would not recommend eliminating them from the instrument. The Revised PDQ, which has been successfully used in a variety of recent studies (Arroyo 2013; Auerbach, Lobel, and Cannella 2014; Cannella, Auerbach, and Lobel 2013; Coussons-Read et al. 2012; Lobel et al. 2008; Yuksel, Akin, and Durna 2014), expands the instrument by the addition of several items that may slightly alter, and perhaps improve the factor structure observed for the original instrument.

Although the Spanish version of the PDQ was applied to a moderately large sample of low-risk pregnant women in the second trimester of pregnancy, this study had some limitations. First, selection of the study sample from only two clinical centers may not have provided a representative sample because it did not include pregnant women from all health centers nor pregnant women who do not visit 
health centers. Further, Spanish was not the first language for a small portion of the women in this study (6.4\%). Additionally, given the cross-sectional design, results only reflected measurement at one time point and thus cannot provide temporal and thus potentially causal relations. Future studies should explore variations in responses and stability of the structure throughout pregnancy. Finally, the potential for reporting and social acceptability biases should be considered as limitations.

Evaluation of the psychometric properties of questionnaires is imperative.

Although the development of psychological questionnaires is a long methological process, studies assessing reliability and validity of measures will improve the quality of psychological assessment and enable more appropriate and effective application in clinical settings (Gourounti et al. 2016).

\section{Implications for research and practice}

Future research may investigate if the dimensions found in the present study are also adequate in representing the experience of women from other cultural backgrounds. Forthcoming studies need to examine these dimensions throughout gestation and assess the potential capability of the PDQ to be associated with adverse outcomes in a population-based sample. Prospective studies could assess the psychometric properties of the PDQ in high-risk pregnant women (Alderdice et al. 2013). Good assessment is an important first step in both research and practice in developing effective care to support women experiencing stress in pregnancy (Gourounti et al. 2016). Health care providers can assess pregnancy-specific stress using the PDQ. The fact that the PDQ is a short pregnancy-specific stress measure may benefit clinical 
practice by starting conversations on specific aspects of pregnancy that women might want additional support.

\section{Conclusions}

The three-factor structure identified in a prior EFA was confirmed in this CFA using a sample of Spanish women with low-risk pregnancies. The results indicated that three factors explained the participants' pattern of responses to ten questions. These factors represented concerns about birth and the baby, emotions and relationships, weight gain and bodily changes. These PDQ factors were significantly correlated with measures of general perceived stress and emotions, indicating good convergent validity. Results indicated that a one-factor structure also provided an adequate fit to the data; this factor represents an underlying pregnancy-specific stress construct. The Spanish version of the PDQ is a reliable and valid instrument to assess stress levels during pregnancy. The results of this study also provide evidence that the dimensions investigated by the PDQ represent significant dimensions of women's experience of distress during pregnancy across different western cultural contexts.

\section{References}

Acock, AC. 2013. Discovering Structural Equation Modeling using Stata, revised edition. Texas: Stata Press.

Alderdice, F., and F. Lynn. 2011. Factor structure of the Prenatal Distress Questionnaire. Midwifery 27:553-559. doi: 10.1016/j.midw.2010.05.003. Alderdice, F., and F. Lynn. 2009. Stress in pregnancy: Identifying and supporting women. British Journal of Midwifery 17:552-559. doi:10.12968/bjom.2009.17.9.43787. 
Alderdice, F., F. Lynn, and M. Lobel. 2012. A review and psychometric evaluation of pregnancy-specific stress measures. Journal of Psychosomatic Obstetrics and Gynecology 33:62-77. doi:10.3109/0167482X.2012.673040.

Alderdice, F., E. Savage-McGlynn, C. Martin, F. McAuliffe, A. Hunter, J. Unterscheider, S. Daly et al. 2013. The Prenatal Distress Questionnaire: an investigation of factor structure in a high-risk population. Journal of Reproductive and Infant Psychology 31(5): 456-464. doi:10.1080/02646838.2013.830210.

Andalusian Ministry of Health. 2010. Pregnancy Health Document: J unta de Andalucia. http:// www.juntadeandalucia.es/salud/sites/csalud/galerias/documentos/_c_3_c_ 1_vida_sana/ embarazo_y_salud/lactancia_materna/cartilla_embarazo.pdf (accessed Octuber 24 2017).

Arroyo, J .P. 2013. Exploring potential risk factors of fetal origins of diabetes: maternal stressors during pregnancy and birth outcomes among women in a hospital in the municipality of Caguas, Puerto Rico. PhD. diss., University of South Florida.

Auerbach, M.V., M. Lobel, D.T. Cannella. 2014. Psychosocial correlates of health-promoting and health-impairing behaviors in pregnancy. Journal of Psychosomatic Obstetrics and Gynecology 35:167-482. doi:10.3109/ 0167482X.2014.943179.

Auerbach, M.V., J . Nicoloro-SantaBarbara, L. Rosenthal, C. Kocis, E. R. Weglarz, C. E. Busso, and M. Lobel. 2017. Psychometric properties of the Prenatal Health Behavior Scalein mid-and late pregnancy. Journal of Psychosomatic Obstetrics and Gynecology 38: 143-151. doi: 10.1080/0167482X.2017.1285899.

Beauducel, A., and P. Y. Herzberg. 2006. On the performance of maximum likelihood versus means and variance adjusted weighted least squares estimation in CFA. Structural 
Equation Modeling: A Multidisciplinary Journal 13:186-203.

doi:10.1207/s15328007sem1302_2.

Bolten, M. I., H. Wurmser, A. Buske-Kirschbaum, M. Papoušek, K. M. Pirke, and D.

Hellhammer. 2011. Cortisol levels in pregnancy as a psychobiological predictor for birth weight. Archives of Womens Mental Health 14:33-41. doi:10.1007/s00737-010-0183-1.

Cannella, D., M. Auerbach, and M. Lobel. 2013. Predicting birth outcomes: Together, mother and health care provider know best. Journal of Psychosomatic Research 75:299-304. doi: 10.1016/j.jpsychores.2013.08.004.

Caparros-Caparros, B., E. Villar-Hoz, J .J uan-Ferrer, and F. Viñas-Poch. 2007. Symptom Check-List-90-R: reliability, normative data and factorial structure in university students. International Journal of Clinical and Health Psychology 7:781-794.

Caparros-Gonzalez, R.A., Garcia-Garcia, I., Mariñas-Lirola, J .C. and Peralta-Ramírez, M.I., 2018. GESTASTRES cohort study protocol on the effects of stress duringpregnancy by measuring the cortisol in women's and newborn's hair. Revista Espanola de Salud Publica 92: e1-e9.

Carlson, K.D., and A. O. Herdman. 2012. Understanding the impact of convergent validity on research results. Organizational Research Methods 15:17-32. doi: $10.1177 / 1094428110392383$.

Chaponniere, P. A. 2009. Acculturation, pregnancy-related stress and birth outcomesin Mexican and Mexican-American women. PhD. diss., Trident University International.

Cohen, S., T. Kamarck, and R. Mermelstein. 1983. A global measure of perceived stress. 
Journal of Health and Social Behavior 24:385-396. doi: 10.2307/2136404.

Coussons-Read, M. E., M. Lobel, J. C. Carey, M. O. Kreither, K. D 'Anna, L. Argys, R. G. Ross, C. Brandt, and S. Cole. 2012. The occurrence of preterm delivery is linked to pregnancy-specific distress and elevated inflammatory markers across gestation. Brain, Behavior and Immunity 26:650-659. doi: 10.1016/j.bbi.2012.02.009.

\section{Curran, P.J ., Bollen, K.A., Chen, F., Paxton, P. and Kirby, J.B. 2003. Finite sampling} properties of the point estimates and confidence intervals of the RMSEA. Sociological

\section{Methods \& Research, 32: 208-252. doi: 10.1177/0049124103256130.}

Derogatis, L.R. 1994. SCL-90-R Symptom Checklist-90-R. Administration, scoringand procedures manual. Minneapolis: National Computer System.

Duthie, L., and R. M. Reynolds. 2013. Changes in the maternal hypothalamicpituitary-adrenal axis in pregnancy and postpartum: Influences on maternal and fetal outcomes. Neuroendocrinology 98:106-115. doi:10.1159/000354702.

Epstein, J ., R. M. Santo, and F. Guillemin. 2015. A review of guidelines for cross-cultural adaptation of questionnaires could not bring out a consensus. Journal of Clinical Epidemiology 68:435-441. doi:10.1016/j.bbi.2012.02.009.

Field, A. (2009). Discovering statistics using SPSS. Sage publications.

Gelaye, B., G. Addae, B. Neway, G.T. Larrabure-Torrealva, C. Qiu, L. Stoner, M. A, LuqueFernandez, S. E. Sanchez, and M. A. Williams. 2017. Poor sleep quality, antepartum depression and suicidal ideation among pregnant women. Journal of Affective Disorders 209: 195-200. doi:10.1016/j.jad.2016.11.020. 
Gennaro, S., J . Shults, and D. J . Garry. 2008. Stress and preterm labor and birth in black women. Journal of Obstetrics, Gynecology and Neonatal Nursing 37:538-545. doi:10.1111/j.1552-6909.2008.00278.x.

Gourounti, K., N. Karpathiotaki, V. Karapanou, P. Antzaklis, and G. Daskalakis. 2016. Validation of the High-Risk Pregnancy Stress Scale in a sample of hospitalized Greek high-risk pregnant women. Women \& Health, 56(6), pp.680694. doi: 10.1080/03630242.2015.1118729.

Heberlein, E.C., A. H. Picklesimer, D. L. Billings, S. Covington-Kolb, N. Farber, and E. A. Frongillo. 2016. The comparative effects of group prenatal care on psychosocial outcomes. Archives of Women's Mental Health 19: 259-269. doi:10.1007/ s00737-0150564-6.

Henderson, J ., J .J omeen, and M. Redshaw. 2018. Care and self-resported outcomes of care experienced by women with mental health problems in pregnancy: Findings from a national survey. Midwifery 56: 171-178. doi: 10.1016/j.midw.2017.10.020.

Hu, L., and P. M. Bentler. 1999. Cutoff criteria for fit indexes in covariance structure analysis: Conventional criteria versus new alternatives. Structural Equation Modeling: A Multidisciplinary Journal 6:1-55. doi:10.1080/ 10705519909540118.

Koletzko, S. H., P. La Marca-Ghaemmaghami, and V. Brandstätter. 2015. Mixed expectations: Effects of goal ambivalence during pregnancy on maternal well-being, stress, and coping. Applied Psychology: Health and Well-Being 7:249-274. doi:10.1111\%2Faphw.12047.

Lobel, M., D. L. Cannella, J . E. Graham, C. DeVincent, J . Schneider, and B. A. Meyer. 2008. Pregnancy-specific stress, prenatal health behaviors, and birth outcomes. Health 
Psychology 27:604-615. doi:10.1037/a0013242.

Lobel, M., C. J . DeVincent, A. Kaminer, and B. A. Meyer. 2000. The impact ofprenatal maternal stress and optimistic disposition on birth outcomes in medically high-risk women. Health Psychology 19:544-553. doi:10.1037/ 02786133.19.6.544.

Lobel, M., and C. Dunkel Schetter. 2016. Pregnancy and prenatal stress. In Encyclopedia of Mental Health, ed. by Friedman HS, 2nd ed., 318-329. Waltham, Massachusetts: Academic Press.

Lynn, F., F. Alderdice, G. E. Crealey, and J . C. McElnay. (2011) Associations between maternal characteristics and pregnancy-related stress among low-risk mothers: An observational cross-sectional study. International Journal of Nursing Studies 48:620-627. doi:10.1016/j.jinurstu.2010.10.002.

Martin, C. R., and E. Savage-McGlynn. 2013. A 'good practice' guide for the reporting of design and analysis for psychometric evaluation. Journal of Reproductive and Infant Psychology 31:449-455. doi:10.1080/02646838.2013.835036.

Matvienko-Sikar, K., and S. Dockray. 2017. Effects of a novel positive psychological intervention on prenatal stress and well-being: a pilot randomised controlled trial. Women and Birth 30: e111-e118. doi:10.1016/j.wombi.2016.10.003.

Nast, I., M. Bolten, G. Meinlschmidt, and D. H. Hellhammer. 2013. How to measure prenatal stress? A systematic review of psychometric instruments to assess psychosocial stress during pregnancy. Paediatric and Perinatal Epidemiology 27:313-322. doi:10.1111/ppe.12051.

Nath, S., E. G. Ryan, K. Trevillion, D. Bick, J . Demilew, J . Milgrom, A. Pickles, and L. M. 
Howard. 2018. Prevalence and identification of anxiety disorders in pregnancy: the diagnostic accuracy of the two-item Generalised Anxiety Disorder scale (GAD2). BMJ OPEN 8: e023766. doi:10.1136/ bmjopen-2018-023766.

National Institute for Health and Care Excellence (NICE). 2015. Antenatal and postnatal mental health: clinical management and service guidance. https:/ / www.nice.org.uk/ guidance/ cg192 (accessed November 04 2018).

National Institute for Health and Care Excellence (NICE). 2015. Preterm labour andbirth. https:// www.nice.org.uk/ guidance/ ng25/ resources/ preterm-labour-and-birth-pdf1837333576645 (accessed Octuber 24 2017).

Peñacoba, C., L. Rodríguez, J . Carmona, and D. Marín. 2017. Agreeableness and pregnancy: Relations with coping and psychiatric symptoms, a longitudinal study on Spanish pregnant women. Women \& Health 19:1-17. doi:10.1080/03630242.2017.1282397.

Pluess, M., M. Bolten, K. M. Pirke, and D. Hellhammer. 2010. Maternal traitanxiety, emotional distress, and salivary cortisol in pregnancy. Biological Psychology 83:169175. doi:10.1016/j.biopsycho.2009.12.005.

Razurel, C., B. Kaiser, J . P. Antonietti, M. Epiney, and C. Sellenet. 2017. Relationship between perceived perinatal stress and depressive symptoms, anxiety, and parental self-efficacy in primiparous mothers and the role of social support. Women \& Health, 57(2):154-172. doi:10.1080/03630242.2016.1157125.

Remor, E. 2006. Psychometric properties of a European Spanish version of the Perceived Stress Scale (PSS). Spanish Journal of Psychology 9:86-93. doi:10.1017/ S1138741600006004.

Rhemtulla, M., P. E. Brosseau-Liard, and V. Savalei. 2012. When can categorical variables be 
treated as continuous? A comparison of robust continuous and categorical SEM estimation methods under suboptimal conditions. Psychological Methods 17:354-373. doi:10.1037/a0029315.

Rosand, G.M., K. Slinning, M. Eberhard-Gran, E. Roysamb, and K. Tambs. 2011. Partner relationship satisfaction and maternal emotional distress in early pregnancy. Biomed Central Public Health 11:161. doi:10.1186/ 1471-2458-11-161.

Royal College of Midwives. 2018. Stress.

https:// www.rcm.org.uk/ sites/ default/ files/ Stress.pdf (accessed November 04 2018).

StataCorp. 2013. Stata: Release 13. College Station: StataCorp LP.

Schreiber, J. B., A. Nora, F. K. Stage, E. A. Barlow, and J . King. 2006. Reporting structural equation modeling and confirmatory factor analysis results: A review. Journal of Educational Research 99, 323-338. doi:10.3200/J OER.99.6.323338.

Levine, T.A., R. E. Grunau, R. Segurado, S. Daly, M. P. Geary, M. M. Kennelly, K. O’Donoghue, A. Hunter, J J . Morrison, G. Burke, P. Dicker, E. Tully, F. Malone, F. Alderdice, and F. MacAuliffe. 2017. Pregnancy-specific stress, fetoplacental haemodynamics, and neonatal outcomes in women with small for gestational age pregnancies: a secondary analysis of the multicentre Prospective Observational Trial to Optimise Paediatric Health in Intrauterine Growth Restriction. BMJ OPEN 7: p.e015326. doi:10.1136/ bmjopen-2016015326. 
Willett, W. C., F. Sacks, A. Trichopoulou, G. Drescher, A. Ferro-Luzzi, E. Helsing, and D. Trichopoulos D. 1995. Mediterranean diet pyramid: a cultural model for healthy eating. American Journal of Clinical Nutrition 61:1402S-6S.

Yali, A. M., and M. Lobel. 1999. Coping and distress in pregnancy: an investigation of medically high risk women. Journal of Psychosomatics Obstetrics and Gynecology 20:39-52. doi:10.3109/01674829909075575.

Yuksel, F., S. Akin, and Z. Durna. 2014. Prenatal distress in Turkish pregnant women and factors associated with maternal prenatal distress. Journal of Clinical Nursing 23:53-64. doi:10.1111/j.1365-2702.2012.04283.x. 
Figure 1 Spanish PDQ mean scores and standard deviations (in brackets) in the study sample for each item $(\mathrm{N}=233)$

Figure 2 Standardized estimates of the final three factors model of the CFA (Model 4) $(\mathrm{N}=233)$ 
Table 1. Sociodemographics and obstetric history of participants $(\mathrm{N}=233)$

\begin{tabular}{|c|c|}
\hline Variables & Frequency $(\%)$ \\
\hline \multicolumn{2}{|l|}{ Sociodemographics } \\
\hline Age group (years) & \\
\hline $19-25$ & $30(12.9)$ \\
\hline $26-35$ & $155(66.5)$ \\
\hline $36-42$ & $48(20.6)$ \\
\hline \multicolumn{2}{|l|}{ Country of origin } \\
\hline Spain & $172(73.8)$ \\
\hline Latin America & $46(19.7)$ \\
\hline Europe (not Spain) & $12(5.1)$ \\
\hline Morroco & $2(0.9)$ \\
\hline Russia & $1(0.4)$ \\
\hline \multicolumn{2}{|l|}{ Marital status } \\
\hline Married/Co-habiting & $225(96.6)$ \\
\hline Single/Separated/Divorced & $8(3.4)$ \\
\hline \multicolumn{2}{|l|}{ Employment } \\
\hline Full-time job & $36(15.5)$ \\
\hline Part-time job & $119(51.1)$ \\
\hline Unemployed & $62(26.6)$ \\
\hline Student & $8(3.4)$ \\
\hline Student and employed & $8(3.4)$ \\
\hline \multicolumn{2}{|l|}{ Level of education completed } \\
\hline Primary School & $15(6.4)$ \\
\hline $\begin{array}{l}\text { Secondary School } \\
\text { University }\end{array}$ & $\begin{array}{l}71(30.5) \\
147(63.0)\end{array}$ \\
\hline \multicolumn{2}{|l|}{ Obstetric history } \\
\hline \multicolumn{2}{|l|}{ Weeks of gestation } \\
\hline $7-15$ & $16(6.9)$ \\
\hline $16-30$ & $206(88.4)$ \\
\hline $31-37$ & $11(4.7)$ \\
\hline \multicolumn{2}{|l|}{ Previous miscarriages } \\
\hline None & $169(72.5)$ \\
\hline 1 miscarriage & $49(21.1)$ \\
\hline 2 miscarriages & $11(4.7)$ \\
\hline 3 or more miscarriages & $4(1.7)$ \\
\hline \multicolumn{2}{|l|}{ Living children } \\
\hline None & $133(57.1)$ \\
\hline 1 child & $79(33.9)$ \\
\hline 2 children & $14(6.0)$ \\
\hline 3 or more children & $7(3.0)$ \\
\hline \multicolumn{2}{|l|}{ Wantedness } \\
\hline I wanted to be pregnant & $200(85.8)$ \\
\hline I did not want to be pregnant then or any time in the future & $33(14.2)$ \\
\hline \multicolumn{2}{|l|}{ Pregnancy method } \\
\hline Spontaneous & $215(92.3)$ \\
\hline In vitro fertilisation & $11(4.7)$ \\
\hline Artificial insemination & $7(3.0)$ \\
\hline
\end{tabular}


Table 2. Fit indices for the Spanish PDQ CFA for the three-factor Models ( $=233)$.

\begin{tabular}{|c|c|c|c|c|}
\hline & Model 1 & Model 2 & Model 3 & Model 4 \\
\hline & $\begin{array}{l}\text { From Alderdice \& Lynn } \\
\qquad(2011)\end{array}$ & Excludes item 2 & $\begin{array}{l}\text { Item } 2 \text { and item } 6 \\
\text { removed }\end{array}$ & $\begin{array}{l}\text { Item } 2 \text { and item } 6 \text { removed; includes associations between } \\
\text { items } 4 \text { and 5, as well as } 9 \text { and } 11 .\end{array}$ \\
\hline $\operatorname{LR} \chi^{2}$ & $\chi^{2}(51)=164.8, p<0.001$ & $\begin{array}{c}\chi^{2}(41)=101.1 \\
p<0.001\end{array}$ & $\begin{array}{c}\chi^{2}(32)=65.1 \\
p<0.001\end{array}$ & $\begin{array}{c}\chi^{2}(30)=47.1 \\
\mathrm{p}<0.001\end{array}$ \\
\hline CFI & 0.86 & 0.90 & 0.94 & 0.97 \\
\hline RMSEA ${ }^{*}$ & $\begin{array}{c}0.098 \\
(90 \% \text { CI } 0.081 \text { to } 0.115)\end{array}$ & $\begin{array}{c}0.079 \\
(90 \% \text { CI } 0.06 \text { to }\end{array}$ & $\begin{array}{c}0.067 \\
(90 \% \text { CI } 0.04 \text { to }\end{array}$ & $\begin{array}{c}0.049 \\
(90 \% \text { CI } 0.01 \text { to } 0.07)\end{array}$ \\
\hline & & $.09)$ & 0.09) & \\
\hline WRMR & 1.105 & 0.920 & 0.769 & 0.640 \\
\hline
\end{tabular}

“Following the standard of reporting for RMSEA, 90\% CI was applied (Curran et al., 2003). 
Table 3. Correlation coefficients between the Prenatal Distress Questionnaire (PDQ), Perceived Stress Scale and Symptom Checklist-90 (SCL90-R) and internal consistency of the PDQ $(\mathrm{N}=233)$

\begin{tabular}{|c|c|c|c|c|c|}
\hline & & \multicolumn{3}{|c|}{ Three-factor Solution } & \multirow[t]{2}{*}{ One-factor solution } \\
\hline & & $\begin{array}{l}\text { Factor } 1 \text { (Birth } \\
\text { Concerns) }\end{array}$ & $\begin{array}{l}\text { Factor } 2 \text { (Physical } \\
\text { Concerns) }\end{array}$ & $\begin{array}{l}\text { Factor } 3 \text { (Relations } \\
\text { Concerns) }\end{array}$ & \\
\hline $\begin{array}{l}\text { Perceived Stress } \\
\text { Scale }\end{array}$ & & $0.29^{* *}$ & $0.18^{* *}$ & $0.30^{* *}$ & $0.321 * *$ \\
\hline \multirow{13}{*}{$\begin{array}{l}\text { SCL-90-R sub- } \\
\text { scales }\end{array}$} & Somatization & $0.411 * *$ & $0.266^{* *}$ & $0.440 * *$ & $0.496 * *$ \\
\hline & Obsession Compulsion & $0.267 * *$ & $0.269 * *$ & $0.337 * *$ & $0.352 * *$ \\
\hline & Interpersonal Sensitivity & $0.296 * *$ & $0.271 * *$ & $0.338 * *$ & $0.344 * *$ \\
\hline & Depression & $0.387 * *$ & $0.230 * *$ & $0.413 * *$ & $0.451 * *$ \\
\hline & Anxiety & $0.383 * *$ & $0.256^{* *}$ & $0.421 * *$ & $0.451 * *$ \\
\hline & Hostility & $0.356 * *$ & 0.149 & $0.318 * *$ & $0.341 * *$ \\
\hline & Phobic Anxiety & $0.224 * *$ & 0.149 & $0.241 * *$ & $0.266^{* *}$ \\
\hline & Paranoid Ideation & $0.246 * *$ & $0.195^{*}$ & $0.285 * *$ & $0.282 * *$ \\
\hline & Psychoticism & $0.284 * *$ & $0.185^{*}$ & $0.261 * *$ & $0.313 * *$ \\
\hline & GSI & $0.386 * *$ & $0.269 * *$ & $0.418 * *$ & $0.447 * *$ \\
\hline & PSDI & $0.333 * *$ & 0.138 & $0.314 * *$ & $0.398 * *$ \\
\hline & Positive Symptom Total & $0.343 * *$ & $0.280 * *$ & $0.400 * *$ & $0.371 * *$ \\
\hline & Cronbach's alpha & 0.642 & 0.529 & 0.684 & 0.743 \\
\hline
\end{tabular}


Note. PSS, Perceived Stress Scale

"p $<0.05$

${ }^{* *} \mathrm{p}<0.01$ 
Table 4. Inter-total Correlation Matrix and Cronbach's alpha if an item was deleted ( $\mathrm{N}=233$ )

\begin{tabular}{lllllllllllll}
\hline & Item1 & Item2 & Item3 & Item4 & Item5 & Item6 & Item7 & Item8 & Item9 & Item10 & Item11 & Item12 \\
Item1 & & & & & & & & & & & & \\
Item2 & 0.355 & & & & & & & & & & & \\
Item3 & 0.049 & 0.188 & & & & & & & & & & \\
Item4 & 0.138 & 0.494 & 0.225 & & & & & & & & & \\
Item5 & 0.156 & 0.283 & 0.087 & 0.348 & & & & & & & & \\
Item6 & 0.023 & 0.001 & 0.206 & 0.057 & -0.018 & & & & & & & \\
Item7 & 0.520 & 0.413 & 0.116 & 0.249 & 0.241 & 0.171 & & & & & & \\
Item8 & 0.262 & 0.210 & 0.321 & 0.219 & 0.257 & 0.219 & 0.346 & & & & & \\
Item9 & 0.206 & 0.207 & 0.131 & 0.060 & 0.092 & 0.102 & 0.149 & 0.195 & & & & \\
Item10 & 0.234 & 0.360 & 0.297 & 0.209 & 0.148 & 0.023 & 0.237 & 0.291 & 0.333 & & & \\
Item11 & 0.087 & 0.246 & 0.211 & 0.132 & 0.063 & 0.031 & 0.086 & 0.171 & 0.409 & 0.441 & & \\
Item12 & 0.046 & 0.177 & 0.121 & 0.176 & 0.218 & -0.129 & 0.091 & 0.232 & 0.113 & 0.237 & 0.263 & \\
Cronbach's alpha & & & & & & & & & & & \\
if item deleted & 0.717 & 0.696 & 0.721 & 0.714 & 0.723 & 0.756 & 0.705 & 0.705 & 0.718 & 0.697 & 0.715 & 0.729 \\
\hline
\end{tabular}


Table S1. Summary of exploratory factor analyses results for the Prenatal Distress Questionnaire $(\mathrm{n}=116)$.

\begin{tabular}{llll}
\hline & & \multicolumn{2}{c}{ Rotated Factor Loadings } \\
& $\begin{array}{l}\text { Factor 1 } \\
\text { Concerns about Birth }\end{array}$ & $\begin{array}{l}\text { Factor 2 } \\
\text { Concerns about Relationships }\end{array}$ & $\begin{array}{l}\text { Factor 3 } \\
\text { Concerns about Physical } \\
\text { Symptoms }\end{array}$ \\
& & & $\mathbf{0 . 6 5}$ \\
Item 1(weight gain) & -0.15 & 0.11 & $\mathbf{0 . 4 3}$ \\
Item 2 (physical symptoms) & 0.32 & 0.39 & -0.12 \\
Item 3 (handling baby) & $\mathbf{0 . 4 4}$ & 0.08 & -0.08 \\
Item 4 (emotional symptoms) & 0.27 & $\mathbf{0 . 9 5}$ & 0.29 \\
Item 5 (relationships people) & -0.01 & $\mathbf{0 . 4 7}$ & 0.04 \\
Item 6 (healthy food) & 0.01 & -0.01 & $\mathbf{0 . 6 8}$ \\
Item 7 (body shape) & -0.11 & 0.13 & 0.23 \\
Item 8 (relationship partner) & 0.07 & $\mathbf{0 . 6 4}$ & 0.24 \\
Item 9 (unhealthy baby) & $\mathbf{0 . 4 1}$ & -0.31 & 0.11 \\
Item 10 (labour and delivery) & $\mathbf{0 . 4 8}$ & 0.11 & -0.04 \\
Item 11 (prematurity) & $\mathbf{0 . 6 3}$ & 0.01 & 0.01 \\
Item 12 (emotional attachment) & $\mathbf{0 . 4 2}$ & -0.04 & 1.41 \\
$\quad$ Eigenvalues & 1.56 & 1.46 & 11.48 \\
\hline
\end{tabular}

Note. Factor loadings $>0.32$ appear in bold. 


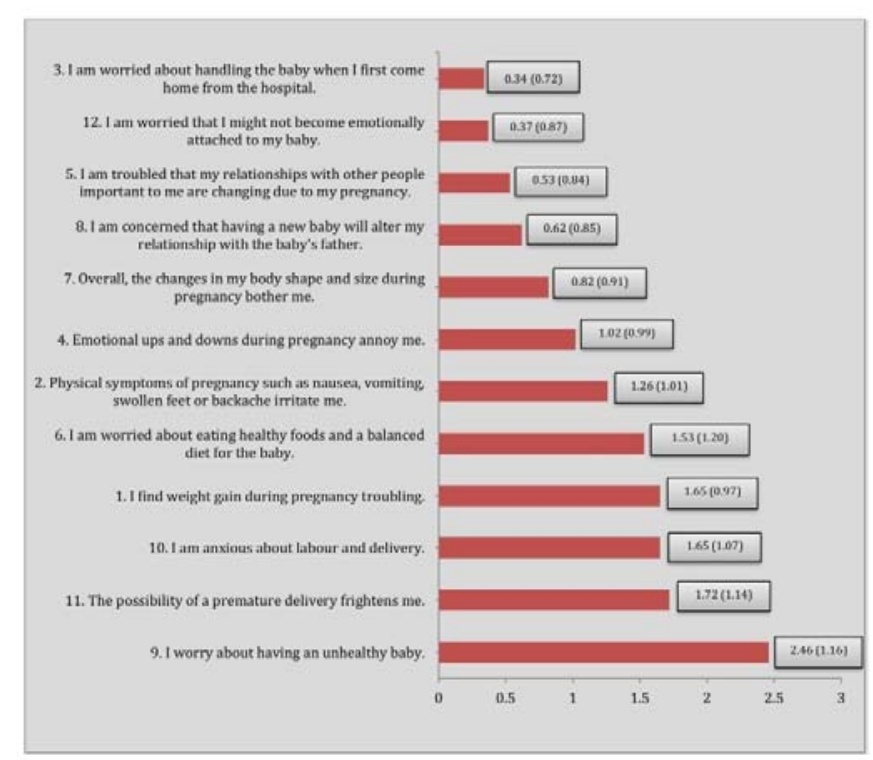

Fig 1 Spanish PDQ mean scores and standard deviations (in brackets) in the study sample for each item (N =233)

$297 \times 209 \mathrm{~mm}(300 \times 300 \mathrm{DPI})$ 


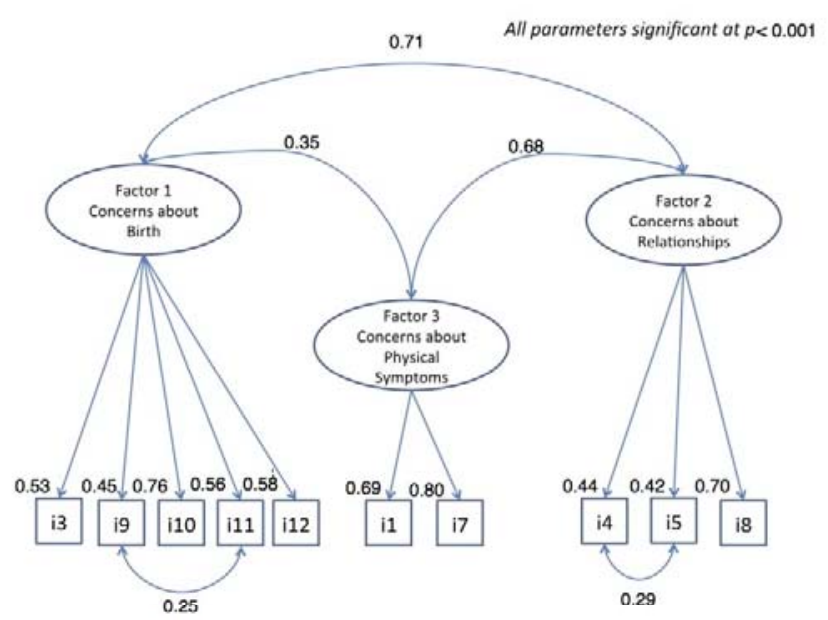

Figure 2 Standardized estimates of the final three factors model of the CFA (Model 4$)(\mathrm{N}=233$ ) $209 \times 296 \mathrm{~mm}(200 \times 200 \mathrm{DPI})$ 